\title{
Separating effects of soil microorganisms and nematodes on plant community dynamics
}

\author{
Minggang Wang • Gerlinde B. De Deyn • \\ T. Martijn Bezemer
}

Received: 13 August 2018 / Accepted: 26 April 2019/Published online: 11 June 2019

(C) The Author(s) 2019

\begin{abstract}
Aims Soil food webs include multiple groups of organisms that each can favor or repress particular plant species in a plant community. This study explores how microbes and nematodes alter the temporal dynamics of specific plant species and functional groups (i.e. grasses and forbs) in mixed grassland communities.

Methods We extracted communities of nematodes and microorganisms from natural grassland soil and inoculated them, separately and in combination, into containers filled with sterilized grassland soil to examine how these groups of soil organisms influence the compositional dynamics of a diverse grassland plant community consisting of 12 species.

Results Addition of soil microorganisms altered the composition of the plant community by enhancing forb species and promoting evenness, but these effects took time to develop and became significant only 6 months after inoculation. Addition of
\end{abstract}

Responsible Editor: François Teste.

Electronic supplementary material The online version of this article (https://doi.org/10.1007/s11104-019-04137-3) contains supplementary material, which is available to authorized users.

M. Wang $(\bowtie) \cdot$ T. M. Bezemer

Department of Terrestrial Ecology, Netherlands Institute of Ecology (NIOO-KNAW), Droevendaalsesteeg 10, 6708

PBWageningen, The Netherlands

e-mail: minggang.wang@slu.se

M. Wang

Department of Plant Protection Biology, Swedish University of Agricultural Sciences, P.O. Box 102, SE-23053, Alnarp, Sweden soil nematodes showed faster effects and reduced plant community evenness via suppressing several subordinate plant species. The nematode community was dominated by root-feeding nematodes that were less abundant when microorganisms were present, indicating a potential inhibitory effect of microorganisms on plant-feeding nematodes.

Conclusions Our results show that soil microorganisms and nematodes may differ in the magnitude and direction of their effects on the compositional dynamics of plant communities in natural grasslands, and that these effects may operate at different timespans. This study highlights the complexity of plant-soil biotic interactions and the importance to explore these interactions at multiple temporal scales.

Keywords Soil biota - Grassland · Temporal dynamics . Soil inoculation $\cdot$ Plant-soil interactions

\author{
G. B. De Deyn \\ Soil Biology Group, Wageningen University and Research, PO \\ Box 47, 6700 AAWageningen, The Netherlands \\ T. M. Bezemer \\ Institute of Biology, Section Plant Ecology and Phytochemistry, \\ Leiden University, PO Box 9505, 2300 RALeiden, \\ The Netherlands
}




\section{Introduction}

Plants compete for nutrients, light and water, but many studies recognize that plant-plant interactions can also be affected by soil biota (e.g. De Deyn et al. 2003; Bezemer et al. 2010; de Kroon et al. 2012; Hendriks et al. 2015; Teste et al. 2017). The soil community comprises a variety of groups that form antagonistic or mutualistic relations with different plant species, and as these interactions influence plant performance this can result in shifts in the relative abundances of the different plant species in mixed communities (Klironomos et al. 2000; Hart et al. 2003; De Deyn et al. 2003). Other groups in the soil community, such as decomposers, can regulate levels of soil nutrients available for plants and this can mediate the performance of slow and fastgrowing plant species differently (Zak et al. 2003; van der Heijden et al. 2008). As the soil comprises many groups of soil organisms with different functions, an important challenge is to disentangle the role of these groups of soil organisms in influencing plant competition and plant community composition (Mills and Bever 1998; Francis and Read 1994; De Deyn et al. 2004a; Schnitzer et al. 2011; Heinze et al. 2015; van der Heijden et al. 2016).

Within the soil community, nematodes are a group of soil organisms that can strongly determine plant growth and plant-plant interactions (Chen et al. 1995; Kardol et al. 2005; Thakur et al. 2014). A soil nematode community is typically composed of multiple feeding groups that can either benefit or harm the performance of a plant (Yeates et al. 1993; Ekschmitt et al. 2001). As herbivores, root-feeding nematodes can directly reduce the competitive ability of the host plant species and thereby indirectly promote the performances of other coexisting non-host plant species (van der Putten and Van der Stoel 1998; Verschoor et al. 2002). Fungal- and bacterial-feeding nematodes may affect plant species indirectly via grazing on fungi and bacteria that results in the release of nutrients locked in the microbes. These released nutrients can be taken up by the plants, and thus indirectly contribute to plant growth (de Ruiter et al. 1993). Similarly, predation on other nematodes by carnivorous nematodes can also increase nutrient availability in the soil, but this group of nematodes can also change plant performance by altering the numbers of the other groups of nematodes (Bongers and Bongers 1998). It is evident that nematodes and plant species can intimately interact, but at the community level, the majority of studies so far have focused on how plant species identity, diversity or community composition influence the composition of the nematode community (De Deyn et al. 2004b; Viketoft et al. 2009; De Long et al. 2016; Cortois et al. 2017). In turn, how soildwelling nematodes as a community influence the composition and diversity of plant communities has received less attention.

Soil microorganisms such as bacteria, fungi and protozoa, regulate multiple key ecological processes in the soil (van der Heijden et al. 2008; Bardgett and van der Putten 2014) and can mediate plant growth, diversity and plant community assemblage (Bradford et al. 2002; Zak et al. 2003; Bever et al. 2010; Wagg et al. 2014; Wang et al. 2019). Organisms such as soil-borne plant pathogens (van der Putten and Peters 1997), mycorrhizal fungi (Scheublin et al. 2007) or symbiotic nitrogenfixing bacteria (van der Heijden et al. 2006), directly affect plant growth and hence plant-plant competition. Moreover, the effects of these organisms on plant interactions may increase with time due to the accumulation of pathogens over time (van der Putten et al. 1993) or the gradual establishment of mutualisms (Peay 2018). Other groups of soil microorganisms e.g. saprotrophs, that do not directly interact with the plant, can alter the availability of nutrients for the plant, and via this mechanism they can also influence plant growth and ultimately the composition of plant communities (Reynolds et al. 2003). It is evident that both nematodes and soil microbes can influence plant growth and plant community composition and diversity via several mechanisms. However, both groups of organisms coexist in the soil and hence, disentangling their roles in influencing plant communities and examining how long this can be maintained is a major challenge.

Recent studies on plant-soil feedbacks have shown that plant species that belong to different functional groups, such as grass and forb species differ in how they respond to changes in the composition of soil biota (Cortois et al. 2016; Heinen et al. 2018). These differences can result from selective effects of soil organisms on specific types or groups of plants. For example, rootfeeding nematodes often reduce biomass of grasses and increase biomass of non-leguminous forbs by preferentially feeding on grass species and thus releasing the competitive pressure on forb species (Viketoft et al. 2005; Wurst et al. 2008). However, there are also several species of root-feeding nematodes that specifically feed on forbs (e.g. De Deyn et al. 2004b), and the generality 
of this warrants further testing. In contrast, soil microorganisms overall tend to negatively influence forb species more than grasses due to the relatively higher $\mathrm{P}$ content in roots of forbs, leading to higher susceptibility of forbs than of grasses to soil-borne pathogens (Laliberté et al. 2015). Hence, inoculating a plant community consisting of grasses and forbs with soil communities of nematodes and microbes can result in shifts in the relative abundance of both plant groups, depending on the inoculated soil community composition and on which component of the soil community has the strongest impact.

In this study, we evaluated soil microbe and/or nematode effects on plant and soil communities in large mesocosms with an experimental grassland community consisting of grasses and forbs. We hypothesize that: (1) soil nematodes reduce the growth of grasses, while soil microorganisms decrease the growth of forbs, (2) soil nematodes and microorganisms alter the diversity and composition of plant communities by affecting plant performance in a plant species-specific way, (3) the impact of soil nematodes and microorganisms on plant species and on the composition of the plant community increases over time.

\section{Materials and methods}

\section{Experimental set-up}

Soil $(800 \mathrm{~kg})$ for this experiment was collected from the upper $10 \mathrm{~cm}$ soil layer using a soil corer in a perennial grassland at “de Born” in Wageningen (51 59 'N, $\left.5^{\circ} 40^{\prime} \mathrm{E}\right)$. The soil was a sandy loam grassland soil with particle size: < $2 \mu \mathrm{m} \mathrm{3 \% ;} \mathrm{2-63} \mu \mathrm{m} \mathrm{17 \% ;>} 63 \mu \mathrm{m} \mathrm{80 \%}$ and $3.5 \%$ organic matter. The soil was immediately sieved $(1 \mathrm{~cm}$ mesh) to remove stones and roots, and then fully mixed and put into plastic bags, and sterilized using gamma irradiation (minimum of $25 \mathrm{~K}$ gray, Isotron Ede, The Netherlands). The experiment used 808 -L containers $(17 \mathrm{~cm} \times 17 \mathrm{~cm}, 20 \mathrm{~cm}$, height $)$ that were filled with $8 \mathrm{~kg}$ sterilized soil each and randomly assigned to one of four treatments (20 replicates per treatment, see below). After filling the mesocosms, the soil was saturated and flushed with $2 \mathrm{~L}$ tap water to remove extra nutrients released due to soil sterilization (Troelstra et al. 2001). Thereafter, the soil was kept at $20 \%(w / w)$ soil moisture. Soil moisture had of the sterilized soil had been determined by weighing fresh soil and oven-dried soil. In each mesocosm a plant community of 12 plant species was planted, with one individual of each plant species. The species included three grasses (Agrostis capillaris, Anthoxanthum odoratum, Festuca ovina), and eight forb species (Achillea millefolium, Campanula rotundifolia, Cerastium fontana, Plantago lanceolata, Prunella vulgaris, Rumex acetocella, Jacobaea vulgaris, Tripleurospermum matricariae) as well as one leguminous species (Lotus corniculatus). These species typically co-occur in natural Dutch restoration grasslands in the Veluwe area. Fewer grass species than forb species were selected as this resembles the composition in natural grasslands in the Netherlands, and considering the overall fast growth of grasses that may result in rapid grass domination in the mesocosms; only one legume species was included to stay close to the balance between legumes and non-leguminous forbs in this system. Seeds of the species were provided by a specialized commercial supplier ("Cruydt-hoeck", Groningen, The Netherlands). Plant seeds were surface sterilized using $4 \%$ hypochlorite and rinsed with demineralized water for $5 \mathrm{~min}$. However, indigenous microbes in seeds may still be present that could be integrated into the soil microbial pool and influence plant growth. Seeds were germinated on sterilized glass beads that were partly submerged in demineralized water and placed in a climate chamber $(16 / 8 \mathrm{~h}$ light/dark, $18 / 22^{\circ} \mathrm{C}$ ). One 2 -week-old seedling of each species was transplanted into each mesocosm. The position of the plants within the mesocosm was randomized. Seedlings that died during the first week were replaced. Not all plants successfully established, and eight mesocosms with seedlings that died after the first week but before the inoculation treatment was applied (after 3 weeks) were omitted from the experiment.

Preparation of nematode and microorganism inocula

Soil for the preparation of microorganism and nematode inocula was collected from the same site ("de Born" in Wageningen) where bulk soil had been collected. This site was grazed and fertilized until 1973 and regularly mown for hay collection twice a year thereafter. The main limiting element for the growth of the nonleguminous grassland plants was nitrogen at the site. Soil was collected using a soil corer $(5.3 \mathrm{~cm}$ in diameter) from the upper $10 \mathrm{~cm}$ layer where soil biota have the strongest interactions with plant roots. The soil was stored in plastic bags at collection and immediately 
transported to the lab and used for microbe and nematode extraction. All inocula were prepared using tap water. The soil microorganism inoculum was made by mixing $5 \mathrm{~kg}$ of soil from the mid-successional grassland with $5 \mathrm{~L}$ tap water. The soil mixture was thoroughly stirred for $1 \mathrm{~min}$ and left for $4 \mathrm{~h}$ to allow large soil particles to settle. The supernatant was sieved through one $75 \mu \mathrm{m}$ sieve followed by two $45 \mu \mathrm{m}$ sieves. The sieves mostly removed the nematodes and arbuscular mycorrizae (AM), including most spores of arbuscular mycorrhizal fungi, but let most non-AM microorganisms and some nematode eggs pass through. Thus, it should be noted that the obtained inoculum of soil microorganisms through this sieving approach may not include a prevalent abundance of AM and may include some nematode eggs. The soil nematode inoculum was extracted from $36 \mathrm{~kg}$ soil suspended in $36 \mathrm{~L}$ tap water using Cobbs' decantation and sieving method (the suspension sequentially went through sieves with $1 \times$ $180 \mu \mathrm{m}$ followed by $1 \times 75 \mu \mathrm{m}$ and $3 \times 45 \mu \mathrm{m}$ meshes). Nematodes were collected from the $75-\mu \mathrm{m}$ and $45-\mu \mathrm{m}$ sieves and incubated for $48 \mathrm{~h}$ on two filters (Hygia favorit, $220 \mathrm{~mm}$; NIPA Instruments, Leeuwarden, The Netherlands). The nematodes were suspended in tap water and stored at $4{ }^{\circ} \mathrm{C}$ until use (less than 1 week). The obtained nematode suspension may not be totally free of soil microbes, but it should at least contain a much lower diversity and a different community composition of soil microbes than the microorganism inoculum due to the high dilution, and because the majority of the microbes were washed through the sieves with the water. The nematode community of four $1 \mathrm{ml}$ samples of the suspension was identified at genus or family level at 50-200× magnification using an inverted light microscope (Olympus CK40, Germany) according to Bongers (1988). The identified nematodes were further allocated to different feeding groups according to Yeates et al. (1993). The inoculated nematode community is presented in Table S1.

Nematode and microorganism inoculation

Three weeks after transplanting, 17 to 19 mesocosms (replicates) were used for initiating four treatments: (1) inoculation with soil microorganisms (MO; $n=17)$; (2) inoculation with soil nematodes $(\mathrm{N} ; n=18)$; (3) inoculation with both soil microorganisms and nematodes $(\mathrm{MO}+\mathrm{N} ; n=18)$; (4) control, inoculation with tap water $(\mathrm{C} ; n=19)$. For each mesocosm $6 \mathrm{~mL}$ inoculum or tap water was injected into the soil with a pipette adjacent to each of the 12 plant positions $(72 \mathrm{~mL}$ per mesocosm). Mesocosms allocated to the $\mathrm{N}$ treatment, received at each position first one $\mathrm{ml}$ of nematode suspension followed by $5 \mathrm{ml}$ of water. Mesocosms allocated to the MO treatment, received $5 \mathrm{ml}$ of microorganism inoculum followed by $1 \mathrm{ml}$ of tap water at each position. Mesocosms allocated to the $\mathrm{MO}+\mathrm{N}$ treatment received first $1 \mathrm{ml}$ of nematode suspension, followed by $5 \mathrm{ml}$ of microorganism inoculum.

All mesocosms were randomly placed in a climate controlled greenhouse compartment at $60 \%$ relative humility, $16 \mathrm{~h}$ light: $8 \mathrm{~h}$ dark, and $20 \pm 1{ }^{\circ} \mathrm{C}$ at day and $14 \pm$ $1{ }^{\circ} \mathrm{C}$ at night. Natural daylight was supplemented by $400 \mathrm{~W}$ metal halide bulbs $\left(1\right.$ per $\left.1.5 \mathrm{~m}^{2}\right)$. Throughout the experiment, light intensities were at least 300 PAR (photosynthetic active radiation) during the day. Within the greenhouse compartment, the mesocosms were rotated once a week to avoid position effects. Each mesocosm was watered regularly and reweighed once a week to reset the soil to the initial moisture level $(20 \%)$.

Plant biomass harvests and nematode extraction

Following the Ecotron approach (Lawton 1996) we terminated plant community assembly by three harvest events (De Deyn et al. 2003) at two, 4 and 6 months after inoculation. Mesocosms were maintained an additional 6 months for another experiment but all microcosms were then caged and herbivorous and carnivorous insects were introduced in a subset of cages (see Bezemer et al. 2005). Because the caging and introduction of insects influenced plant growth greatly, here we only focus on the first 6 months when belowground data of the plant community were not collected. Therefore, at each harvest, only aboveground biomass in each mesocosm was harvested by clipping aboveground tissues of all plant species at $4 \mathrm{~cm}$ above the soil surface. Biomass from each species was kept separate, and all plant material was oven-dried at $70{ }^{\circ} \mathrm{C}$ for 2 days and weighed. At the last harvest (6 months after inoculation), three soil cores ( $1 \mathrm{~cm}$ in diameter) were taken from the top $10 \mathrm{~cm}$ soil layer of each mesocosm and bulked to one soil sample per mesocosm. In order to reduce the number of soil samples and minimize sampling bias for nematode analysis we combined five to seven replicates of a treatment depending on the total number of replicates of that treatment (17-19 replicates). This resulted 
in three different/independent composite soil samples for each of the four treatments. Nematodes were extracted from $100 \mathrm{~g}$ of fresh soil from each of these twelve soil samples using the Oostenbrink extraction technique (Oostenbrink 1960). A subset of each soil sample was oven-dried to measure soil moisture $(w / w)$ so that the abundance of nematodes could be expressed per $100 \mathrm{~g}$ of dry soil. In $10 \%$ of the extracted volume $(10 \mathrm{ml}$ fixed nematode suspension), all nematodes were then counted and identified to different feeding groups according to Yeates et al. (1993).

\section{Data analysis}

For each mesocosm, the biomass of each plant species was determined and expressed as a proportion of total biomass of the plant community. The total biomass and the proportional biomass of grasses and forbs, and the evenness were then calculated. Evenness was calculated as Shannon- evenness J' $=-\sum\left(p_{i} \times \ln p_{i}\right) \times 1 / \ln \mathrm{S}$. In the equation, $\mathrm{p}_{\mathrm{i}}$ represents the proportional biomass of the $i^{\text {th }}$ species in the community and $\mathrm{S}$ the number of species present in each mesocosm. Plant biomass and evenness data were then analyzed using two-way repeated measures ANOVA. In the model, N (present or absent), MO (present or absent) and their interactions with time of harvest (Time: 2, 4 and 6 months) were included as fixed factors, and mesocosm identity as a random factor to account for the repeated measures. A repeated-measure multivariate analysis of variance (MANOVA) was carried out first to examine the overall effects of $\mathrm{N}$ and $\mathrm{MO}$ on the biomasses of all individual plant species together in the community over time (Time as repeated factor). Biomass data of all individual species was square-root transformed to meet the assumption of ANOVA for normality and homogeneity of variance of the residuals. Repeated measures ANOVA was carried out using $\mathrm{R}$ version 3.4.1 (R Core Team 2016) with the "lme4" package.

The effects of the inoculation treatments on plant community composition were examined using principle component analysis (PCA) of the proportion of biomass of each species per mesocosm at each harvest. To visualize changes in the composition we plotted the mean sample scores for each of the four treatments at each harvest. To determine the temporal changes of the plant community in our mesocosms following addition of soil microorganisms and nematodes over three harvests, principal response curves (PRCs) were used (van den
Brink and ter Braak 1999). We plotted the changes of plant community composition over time $(2,4$ and 6 months after addition of soil inocula) for experimental treatments $(\mathrm{MO}, \mathrm{N}, \mathrm{MO}+\mathrm{N})$ deviated from the control treatment $(\mathrm{C})$ represented as a zero line. In this analysis, all treatments $(\mathrm{C}, \mathrm{MO}, \mathrm{N}, \mathrm{MO}+\mathrm{N}) \times$ time of harvest $(2$, 4, 6 months after inoculation) were included as the explanatory variables. Significance of the first axis of the PRC was assessed using a Monte Carlo permutation test $(n=999)$. Each species weight in the PRC diagrams represents the affinity of a plant species with the analyzed treatments. Positive values of species weights suggest increases and negative values suggest decreases of a species with the treatments, and values close to zero indicate no responses of species to treatments. The PRC analysis was performed using the 'prc' function with the "vegan" package in $\mathrm{R}$ version 3.4.1.

Linear regression was used to quantify how well the soil nematode community predicted plant community diversity at the end of experiment (6 months after soil inoculation). The proportion of root-feeding nematodes in the nematode community was calculated for each composite soil sample and both this proportion and total nematode abundance were regressed against the Shannon evenness of the plant community. The Evenness was averaged for corresponding mesocosm replicates from which each composite soil sample derived (5-7 replicates). Residuals were checked for the normality and homogeneity of variance. The regression analyses were performed using the " $\mathrm{lm}$ " function. All the figures were made with the package "ggplot2" in $\mathrm{R}$ version 3.4.1 (R Core Team 2016).

\section{Results}

Inoculation of soil microbes resulted in higher forb biomass and lower grass biomass relative to the control and nematode only treatments (Fig. 1a, b). This effect was particularly visible during the third harvest resulting in a significant Time $\times \mathrm{MO}$ interaction for grass and forb biomass and for the proportion of forb biomass (Table 1). Overall, the biomass of grasses increased over time, while the biomass of forbs declined, resulting in a highly significant main effect of time (Table 1). Forb and grass biomass was not influenced by nematode inoculation. However, evenness of the plant community was reduced by nematode inoculation (Table 1, Fig. 1d). Nematodes suppressed the growth of species F. ovina 

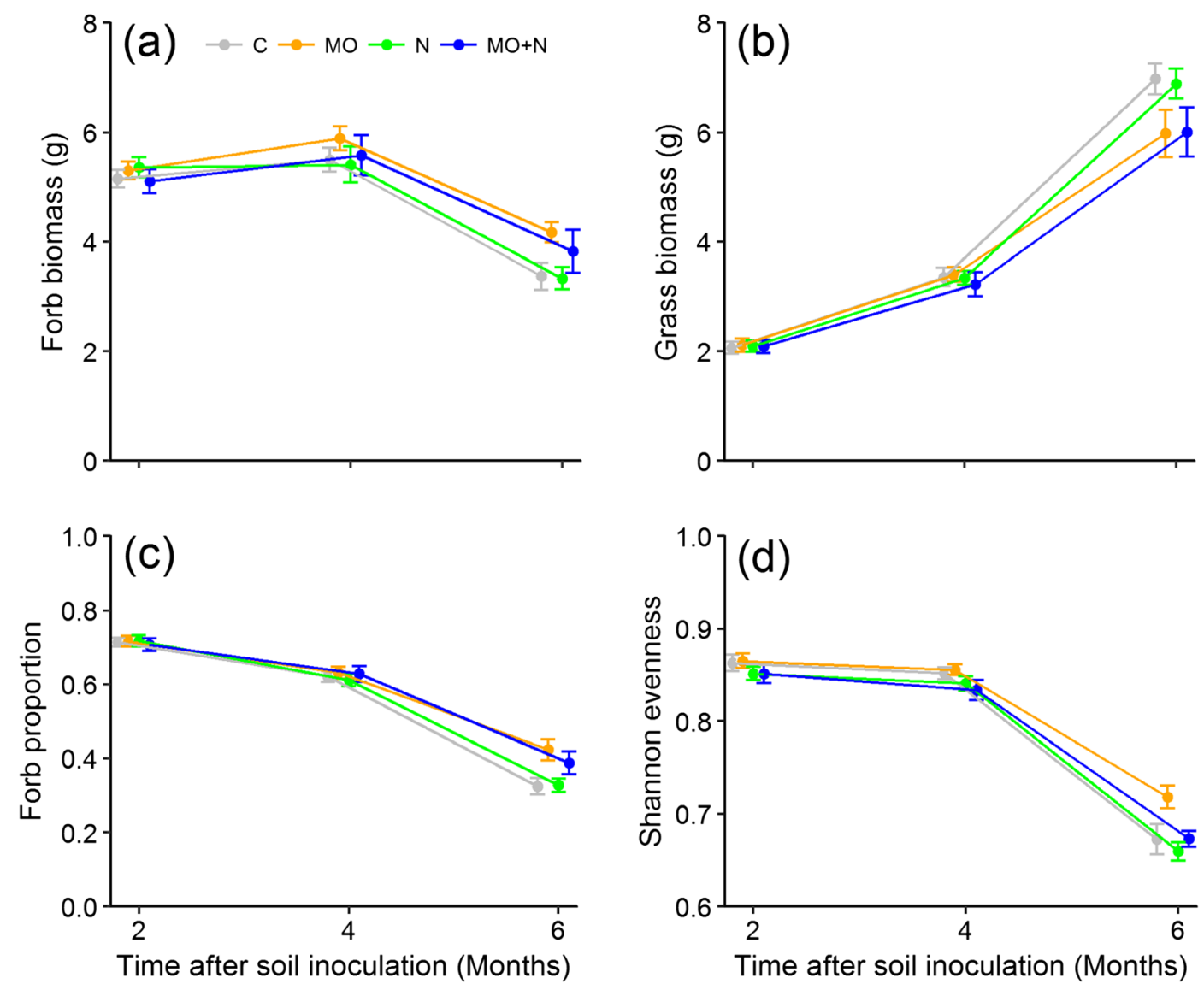

Fig. 1 Mean ( \pm SE) (a) aboveground biomass of forbs, (b) aboveground biomass of grasses, (c) proportion of total biomass allocated to forbs, and (d) evenness of the plant community biomass. Plants were harvested 2, 4 and 6 months after inoculation with soil

microorganisms (MO, brown), soil nematodes $(\mathrm{N}$, green), both soil microorganisms and soil nematodes $(\mathrm{MO}+\mathrm{N}$, blue) or neither (C, grey). $n=17-19$

Table 1 Results from repeated measures ANOVA testing the effects of inoculation of soil microorganisms (MO) or nematodes (N) on aboveground biomass of forbs, grasses, the proportion of forb biomass and plant community evenness. Plants were

harvested after 2, 4 and 6 months (Time). Bold values indicate statistical significances at $P<0.05$. Shown are degrees of freedom (df) and $\mathrm{F}$ and $P$ values $(n=17-19)$

\begin{tabular}{|c|c|c|c|c|c|c|c|c|c|c|}
\hline \multirow[t]{2}{*}{ Source } & \multirow[t]{2}{*}{ Num df } & \multirow[t]{2}{*}{ Den $\mathrm{df}$} & \multicolumn{2}{|c|}{ Forb biomass } & \multicolumn{2}{|c|}{ Grass biomass } & \multicolumn{2}{|c|}{ Forb proportion } & \multicolumn{2}{|c|}{ Evenness } \\
\hline & & & $\mathrm{F}$ & $\mathrm{P}$ & $\mathrm{F}$ & $\mathrm{P}$ & $\mathrm{F}$ & $\mathrm{P}$ & $\mathrm{F}$ & $\mathrm{P}$ \\
\hline MO & 1 & 68 & 2.09 & 0.15 & 2.81 & 0.098 & 3.13 & 0.081 & 1.81 & 0.18 \\
\hline $\mathrm{N}$ & 1 & 68 & 0.40 & 0.53 & 0.04 & 0.83 & 0.27 & 0.60 & 7.48 & 0.008 \\
\hline $\mathrm{MO} \times \mathrm{N}$ & 1 & 68 & 0.59 & 0.45 & 0.01 & 0.93 & 0.19 & 0.66 & 1.10 & 0.30 \\
\hline Time $(\mathrm{T})$ & 2 & 136 & 117.8 & $<0.0001$ & 595.2 & $<0.0001$ & 774.0 & $<0.0001$ & 571.3 & $<0.0001$ \\
\hline $\mathrm{MO} \times \mathrm{T}$ & 2 & 136 & 3.42 & 0.036 & 8.53 & 0.0003 & 11.6 & $<0.0001$ & 4.43 & 0.014 \\
\hline $\mathrm{N} \times \mathrm{T}$ & 2 & 136 & 0.38 & 0.68 & 0.08 & 0.93 & 0.27 & 0.762 & 1.12 & 0.33 \\
\hline $\mathrm{MO} \times \mathrm{N} \times \mathrm{T}$ & 2 & 136 & 0.06 & 0.95 & 0.14 & 0.87 & 0.69 & 0.50 & 0.86 & 0.43 \\
\hline
\end{tabular}


(by $7 \%, 20 \%$ and $22 \%$ at the three harvests, respectively), C. fontana (by $45 \%, 46 \%$ and $43 \%$ respectively) and L. corniculatus $(21 \%, 18 \%$ and $1 \%$, respectively; Table S2, Fig. 2). Inoculation with soil microorganisms led to an increase in evenness but only at the third harvest (Table 1, Fig. 1d). At the final harvest, biomass of the plant species $A$. odoratum was reduced by $13 \%$ by microorganism addition while biomass of $R$. acetocella increased by $68 \%$ and C. fontanum by $12 \%$ in mesocosms inoculated with microorganisms as compared to the control.

The overall principal response curve (PRC) model accounted for $51.1 \%$ of the total variation in plant community composition and the first PRC axis explained $61.7 \%$ of this (Fig. 3, F $=8.69, P=$ $0.045)$. The results revealed that species in the community differently responded to the inoculations of soil nematodes and/or microorganisms and that the community diverged over time. Species weights on the first PRC axis showed that there was a higher proportion of $R$. acetosella biomass but a lower proportion of $A$. odoratum biomass in communities in the $\mathrm{MO}$ and $\mathrm{MO}+\mathrm{N}$ treatments. In contrast, an opposite pattern occurred in communities of the $\mathrm{N}$ treatment relative to the $\mathrm{C}$ treatment. Biomass of other plant species in the communities did not differ between the treatments. The $\mathrm{MO}$ and $\mathrm{MO}+\mathrm{N}$ treatments followed a similar pattern in plant communities over time, suggesting that MO inoculation drove the effects of the $\mathrm{MO}+\mathrm{N}$ treatment (Fig. 3).

At the final harvest, the mean proportion of plantfeeding nematodes was highest in the $\mathrm{N}$ treatment and progressively decreased in the $\mathrm{MO}+\mathrm{N}, \mathrm{MO}$ and $\mathrm{C}$ treatments (Table 2). Other feeding groups followed a similar pattern except fungivores that depauperated in the $\mathrm{N}$ and $\mathrm{MO}+\mathrm{N}$ treatments. There was a negative relationship between plant community evenness and the proportion of plant-feeding nematodes in the nematode community at the final harvest (Fig. 4a). Plant community evenness did not correlate with the total abundance of nematodes in the community (Fig. 4b).
Fig. 2 Proportional aboveground biomass of each plant species in the experimental mesocosms. Means are shown for mesocosms inoculated with microorganisms (MO), soil nematodes $(\mathrm{N})$, both soil microorganisms and soil nematodes $(\mathrm{MO}+\mathrm{N})$ or neither (C, grey) and harvested at 2, 4 and 6 months after inoculation. $n=17-19$. Agrcap - Agrostis capillaris; Antodo -

Anthoxanthum odoratum;

Fesovi - Festuca ovina;

Achmil - Achillea millefolium;

Camrot - Campanula

rotundifolia; Cerfon - Cerastium

fontana; Jacvul - Jacobaea vulgaris; Plalan - Plantago lanceolata; Pruvul - Prunella vulgaris; Rumace - Rumex acetosella; Trimat -

Tripleurospermum matricariae;

Lotcor - Lotus corniculatus

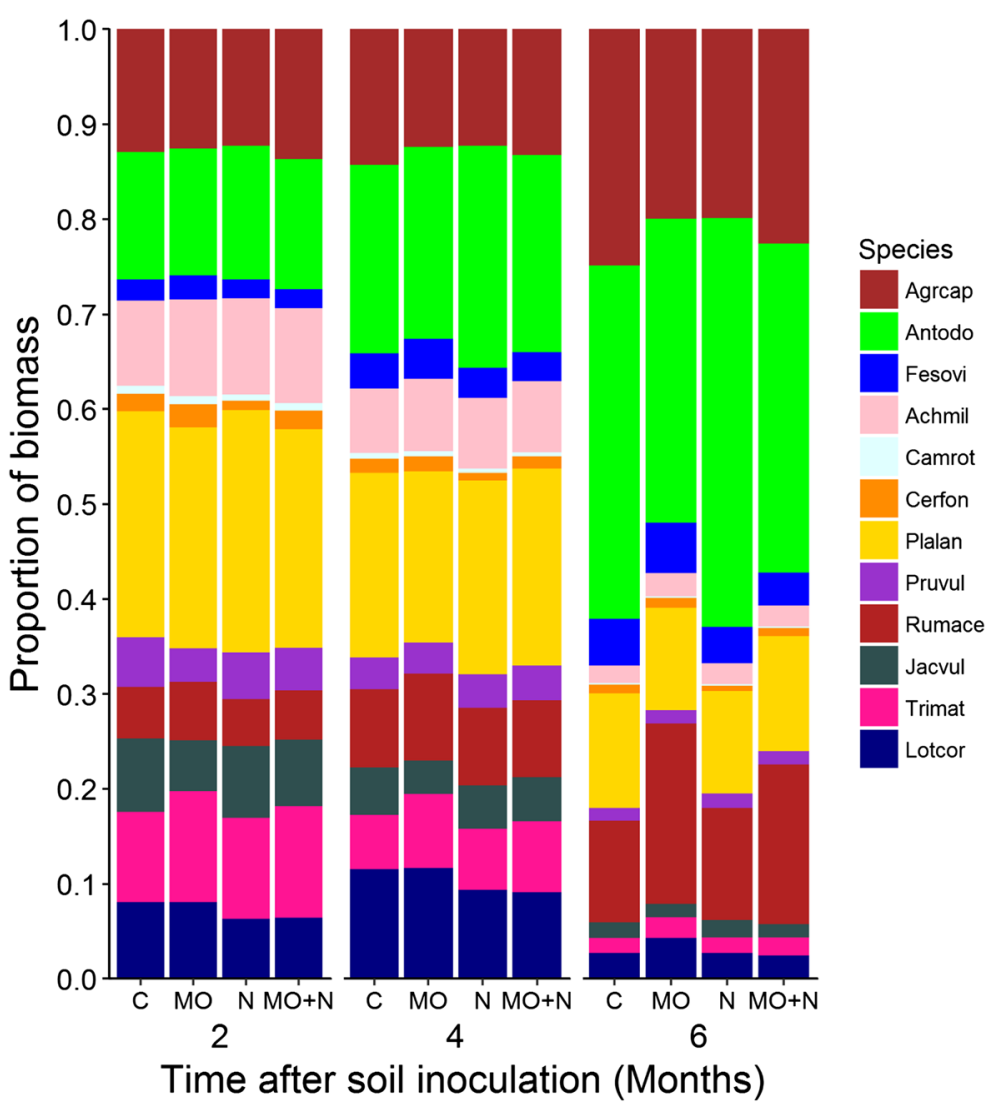




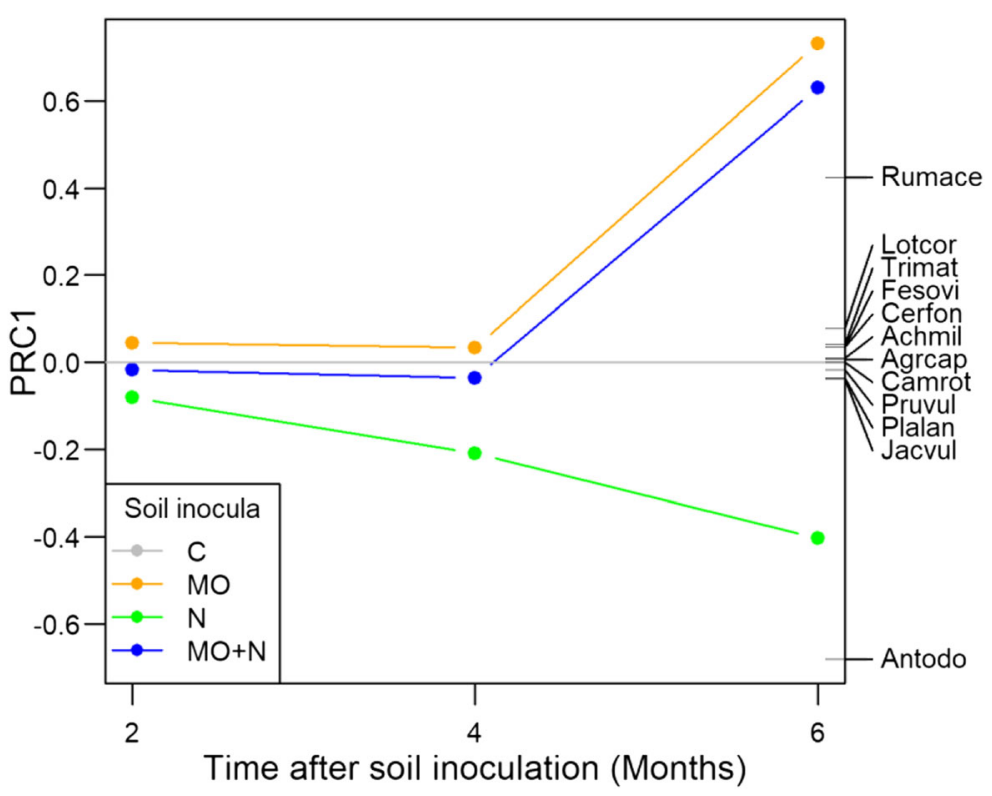

Fig. 3 Principal response curves (PRCs) showing temporal changes in plant communities in response to inoculation of soil microorganisms (MO, brown), soil nematodes $(\mathrm{N}$, green), both soil microorganisms and soil nematodes $(\mathrm{MO}+\mathrm{N}$, blue) relative to control treatment $(\mathrm{C}$, grey), indicated as a horizontal line along the time axis (first axis) representing months after inoculation. The vertical one-dimensional plot at the right side shows the species weights compared to the control treatment. Positive scores indicate increases and negative scores indicate declines in species proportion of total community biomass. By combining the scores from

\section{Discussion}

Our study examined roles of two major soil organism groups, nematodes and microorganisms, in the assembly of a typical grassland plant community over three harvests. The composition of the nematode community at the final harvest was also determined to understand the

Table 2 Mean ( \pm SE) of proportion of plant-feeding (Herbivores), bacterial-feeding (Bacterivores), fungal-feeding (Fungivores), omnivorous (Omnivores) and predatory (Carnivores) nematodes and total number of nematodes in $100 \mathrm{~g}$ soil for each treatment at the end of the experiment, i.e., 6 months after the start of the
PRC curves, these species weight values can predict the relative changes of a species in proportion of total community biomass of a treatment at a particular time. $n=17-19$. Achmil - Achillea millefolium; Agrcap - Agrostis capillaris; Antodo - Anthoxanthum odoratum; Camrot - Campanula rotundifolia; Cerfon - Cerastium fontana; Fesrub - Festuca ovina; Jacvul - Jacobaea vulgaris; Lotcor - Lotus corniculatus; Plalan - Plantago lanceolata; Pruvul - Prunella vulgaris; Rumace - Rumex acetosella; Trimat Tripleurospermum matricariae

causes of these impacts. Three key findings arise from this study: first, soil microorganisms tend to alter plant community composition via promoting forbs and inhibiting grasses. Second, soil microorganisms can enhance plant community evenness, probably by impairing dominating species or enhancing subordinate species. However, this effect develops over time, more so than

\begin{tabular}{lllll}
\hline Feeding groups & $\mathrm{C}$ & $\mathrm{MO}$ & $\mathrm{N}$ & $\mathrm{MO}+\mathrm{N}$ \\
\hline Herbivores (\%) & $19.1 \pm 15.6 \mathbf{a}$ & $6.0 \pm 5.2 \mathbf{a}$ & $87.4 \pm 2.9 \mathbf{c}$ & $71.8 \pm 7.1 \mathbf{b}$ \\
Bacterivores (\%) & $75.3 \pm 12.9 \mathbf{a}$ & $93.6 \pm 5.0 \mathbf{b}$ & $12.4 \pm 2.8 \mathbf{b}$ & $27.8 \pm 7.0 \mathbf{b}$ \\
Fungivores (\%) & $5.6 \pm 5.6 \mathbf{a}$ & $0.02 \pm 0.02 \mathbf{a}$ & $0.02 \pm 0.02 \mathbf{a}$ & $0.06 \pm 0.03 \mathbf{a}$ \\
Omnivores (\%) & 0 & $0.02 \pm 0.02$ & 0 & 0 \\
Carnivores (\%) & 0 & 0 & 0 & 0 \\
Total number & $134 \pm 71$ & $2027 \pm 342$ & $27,274 \pm 4369$ & $11,919 \pm 3727$ \\
\hline
\end{tabular}




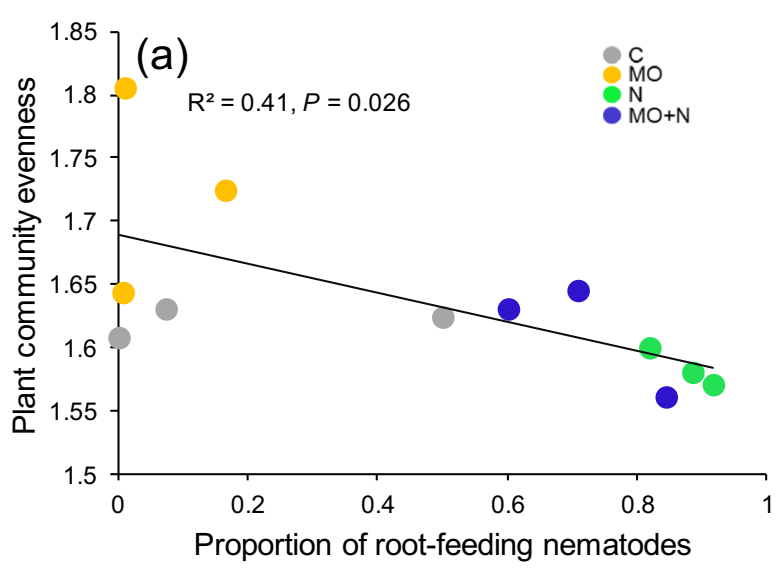

Fig. 4 Relationship between the evenness of the plant community and (a) the proportion of plant-feeding nematodes, and (b) the total abundance of nematodes extracted from soil at the end of experiment, i.e., 6 months after the soil inoculation. Nematodes were extracted from $100 \mathrm{~g}$ composite soil samples $(n=3)$ from the

for nematode addition effects. Third, soil nematodes can reduce plant community evenness, probably due to the effects of root-feeding nematodes that suppress subordinate species, and this reduction acts rapidly.

Many studies have shown that soil microorganisms influence certain plant species or groups by forming specific relations with them, and this can lead to changes in plant community composition (e.g. Reynolds et al. 2003; Eskelinen et al. 2009; Hodge and Fitter 2013; Classen et al. 2015). In line with these previous studies, our study also shows that soil microorganisms resulted in a shift of the plant community, i.e. a higher proportion of forbs, after 6 months of inoculation. This higher forb proportion resulted from both higher forb biomass after soil microorganism inoculation and from a reduction in grass biomass. Overall, in the current study forb species appeared to benefit from soil microbial inoculation more than grass species, which is congruent with expectations postulated based on plant-soil feedback experiments (Kulmatiski et al. 2008; Cortois et al. 2016). Potential explanations can be: (1) forb species benefit from symbiotic microbes more than grass species due to their higher dependence on these symbionts than grass species (Kulmatiski et al. 2014; Pellkofer et al. 2016; Martinez-Garcia et al. 2017), and (2) grass species are more sensitive to microbial pathogens than forb species (Cortois et al. 2016). Our results confirm the prediction that soil microbial inoculum has a greater net negative feedback on grasses than on forbs when it originates from grassland soil (van der Putten et al. 2013). We noted that the effect of soil microorganisms on plant

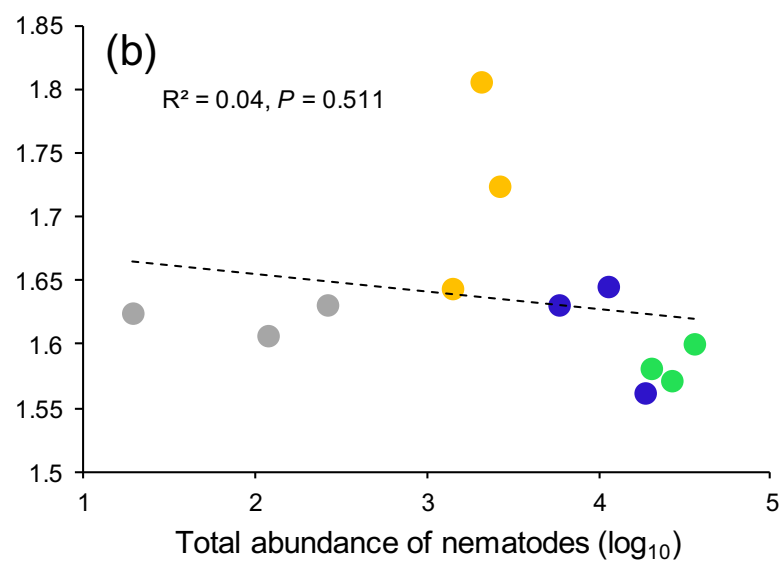

following treatments: inoculated with soil microorganisms (MO, brown), soil nematodes ( $\mathrm{N}$, green), both soil microorganisms and soil nematodes $(\mathrm{MO}+\mathrm{N}$, blue) or neither ( $\mathrm{C}$, grey). Each composite sample was merged from samples of 5 to 7 replicates out of the total 17 to 19 replicate mesocosms of a treatment

species was highest at the final harvest, which may be either due to the accumulation of functional microbes over time or the depletion of available nutrients when these microbes best function. For example, when the availability of particular nutrients in a soil, e.g. phosphorus, starts to become depleted due to plant foraging, arbuscular mycorrhizal fungi (AMF) usually function better in promoting plant growth and this function tends to become stronger over time after AMF establishment (Smith and Read 2008). However, due to the exclusion of most AMF from the microorganism inocula, we speculate that other symbiotic microbes, e.g. rhizobacteria, are more involved than AMF. It is important to note that the grasses and the forb P. lanceolata regrew better than other forbs after repeated harvests. The repeated clippings may have promoted the competitive advantage of grasses over forbs and this may have caused accumulation of soil microbial pathogens in the mesocosms, providing another explanation for increased suppression of grasses by soil microorganisms over time. Unfortunately, neither microbial communities nor available nutrients was determined in the current study making it impossible to verify these pathways. Clearly, microbial and nutrient analyses in soils of multiple origins and their impact on plant community dynamics are needed to test the generality of our results.

Soil nematode communities comprise multiple feeding groups and each group may affect a plant species in a specific way (Trudgill 1991; De Deyn et al. 2004a; Wurst et al. 2008). In our study, we indeed found that inoculation of soil nematodes influenced certain plant species or 
groups more than the others. At the final harvest, the extracted nematode communities were dominated by root-feeding nematodes and these plant parasitic nematodes probably were the main reason for the strong reduction of the biomass of particular plant species such as the grass $F$. ovina, and the forbs $C$. fontana and L. corniculatus. As the nematodes affected a subset of plants in both plant functional groups grasses and forbs, nematode addition caused only a weak effect at the plant functional group level. This result suggests that soil nematodes from a mixed species grassland may not be as specialized as soil microorganisms in colonizing plant species with similar functional traits. However, this finding contradicts with a study by Wurst et al. (2008) showing that soil nematodes significantly reduced the grass biomass but increased forb biomass in a grassland community. This contradiction may be due to the shorter period of community development in this study (2.5 months) compared to the current study (6 months), considering the timing-dependency of such nematode effects. Alternatively, clipping in our study may have caused changes in root exudates, root biomass or root quality and this may also have changed the abundance of root-feeding nematodes in the soil (Wang et al. 2017). Moreover, two of the three plant species that were reduced by nematodes (F. ovina and C. fontana) are subordinate species in our study (with an average percentage of the total biomass of less than 5\% across treatments at a harvest), leading to a nematode-induced reduction in plant community evenness. This finding suggests that specific interactions between plant species and soil nematodes can alter plant community diversity, particularly when these interactions target subordinate or dominant species in the community (Wardle et al. 2003). In addition, given that plant community evenness negatively related to the proportion of root-feeding nematodes instead of the overall abundance of all nematodes in the community, we highlight that soil nematode community composition may be more informative than the total density of nematodes in accounting for the changes in plant community diversity.

Soil microorganisms may contribute to plant community diversity in a different way than soil nematodes because the former contain both prevalent microbial beneficial symbionts and harmful pathogens that can be highly specialized and selective towards their host plants (Zak et al. 2003; van der Heijden et al. 2008; Mordecai 2011). In our study, we did not identify the composition of the soil microorganism inoculum. However, the pathogens and symbionts that were likely present in the soil microorganism inoculum or even indigenous microbes inside of seeds may have affected the performance of specific plant species (Umbanhowar and McCann 2005; Maron et al. 2011). Surprisingly, in contrast to the study of Wurst et al. (2008), our results showed an increased community evenness with the inoculation of soil microorganisms although this was only manifested after 6 months. For this harvest time, we found that the increased plant community evenness mostly originated from a negative effect of soil microorganisms on the highly dominant grass species A. odoratum (with an average percentage of the total biomass more than $25 \%$ across treatments at a harvest). Such negative effect may arise from an overruling negative effect of host-specific pathogens over the positive effect of beneficial rhizobacteria or mycorrhiza in the soil microbial community (Kardol et al. 2007; Cortois et al. 2016). On the other hand, another abundant species $R$. acetosella showed a positive response to inoculation of soil microorganisms at this final harvest, which may in contrast have reduced community evenness although this reduction seems concealed by the opposite responses of $A$. odoratum. Given that $R$. acetosella is a typically non-mycorrhizal forb species (Wang and Qiu 2006) and is often a strong competitor for nutrients in grasslands (Reynolds et al. 2007), we speculate that this positive response may have been caused by an increase in nutrient availability in soil that provides competitive advantages for $R$. acetosella over other species. The increased available nutrients was either contained in the microorganism inoculum or created by the microbial decomposers therein. However, the amount of inoculum added represents only a minor amount of added solution relative to the amount of background soil in the mesocosms so that indirect effects seem more plausible than direct fertilization effects.

Interestingly, in this study soil microorganisms and nematodes not only steered plant communities into different directions, but this also happened at different timespans. Although inoculated at the same time, we found that soil nematodes started to reduce plant community evenness already at the first harvest, whereas soil microorganisms enhanced the evenness but only 4 months later, i.e. at the final harvest. Considering secondary consumers including soil nematodes appear to be less responsive to plant identity than primary consumers such as soil microbes (Wardle et al. 2003; Porazinska et al. 2003), soil nematodes might be more generalistic than soil microorganisms in forming 
relations with their host plants in a given community. Therefore, soil nematodes may require less time to recognize and colonize these plants, resulting in a faster impact on the compositional shift of a species-rich plant community than soil microorganisms in this study.

Soil microorganisms and soil nematodes differ in driving compositional changes of plant communities. Soil microorganisms promote forb species but inhibit grass species, thus exhibiting a strong force in altering the compositions. Soil nematodes did not show a clear effect on the plant community composition, but reduced community diversity by selectively suppressing subordinate plant species (van Ruijven et al. 2005). Moreover, soil microorganisms and soil nematodes also differ in the timing of their effects, with a quicker effect of soil nematodes than soil microorganisms on plant community composition. We conclude that understanding functions of soil biota in assembly of plant communities needs long-term studies linking functional traits of both plant and soil communities.

Acknowledgements We thank Sebastiaan Verkade for practical assistance and Matthew Bowker as well as the anonymous reviewers for their helpful comments on the previous versions of the manuscript. TMB was funded by the Netherlands Organization for Scientific Research (NWO VICI grant 865.14.006) and MW was granted by Carl Tryggers Foundation (CTS 15:468). This is publication no. 6726 of the Netherlands Institute of Ecology (NIOOKNAW).

\section{Compliance with ethical standards}

Conflict of interest The authors declare that they have no conflict of interest.

Statement The authors declare that the experiments comply with the current laws of the Netherlands where the experiments were performed.

Open Access This article is distributed under the terms of the Creative Commons Attribution 4.0 International License (http:// creativecommons.org/licenses/by/4.0/), which permits unrestricted use, distribution, and reproduction in any medium, provided you give appropriate credit to the original author(s) and the source, provide a link to the Creative Commons license, and indicate if changes were made.

\section{References}

Bardgett RD, van der Putten WH (2014) Belowground biodiversity and ecosystem functioning. Nature 515:505-511
Bever JD, Dickie IA, Facelli E, Facelli JM, Klironomos J, Moora M, Rillig MC, Stock WD, Tibbett M, Zobel M (2010) Rooting theories of plant community ecology in microbial interactions. Trends Ecol Evol 25:468-478

Bezemer TM, De Deyn GB, Bossinga TM, Van Dam NM, Harvey JA, van der Putten WH (2005) Soil community composition drives aboveground plant-herbivore-parasitoid interactions. Ecol Lett 8:652-661

Bezemer TM, Fountain MT, Barea JM, Christensen S, Dekker SC, Duyts H, van Hal R, Harvey JA, Hedlund K, Maraun M, Mikola J, Mladenov AG, Robin C, de Ruiter PC, Scheu S, Setala H, Smilauer P, van der Putten WH (2010) Divergent composition but similar function of soil food webs of individual plants: plant species and community effects. Ecology 91:3027-3036

Bongers T (1988) De Nematoden van Nederland. In: KNNV. Utrecht, The Netherlands

Bongers T, Bongers M (1998) Functional diversity of nematodes. Appl Soil Ecol 10:239-251

Bradford MA, Jones TH, Bardgett RD, Black HIJ, Boag B, Bonkowski M, Cook R, Eggers T, Gange AC, Grayston SJ, Kandeler E, McCaig AE, Newington JE, Prosser JI, Setala H, Staddon PL, Tordoff GM, Tscherko D, Lawton JH (2002) Impacts of soil faunal community composition on model grassland ecosystems. Science 298:615-618

Chen SY, Dickson DW, Mitchell DJ (1995) Effects of soil treatments on the survival of soil microorganisms. J Nematol 27: 661-663

Classen AT, Sundqvist MK, Henning JA, Newman GS, Moore JAM, Cregger MA, Moorhead LC, Patterson CM (2015) Direct and indirect effects of climate change on soil microbial and soil microbial-plant interactions: what lies ahead? Ecosphere 6:130

Cortois R, Schroder-Georgi T, Weigelt A, van der Putten WH, De Deyn GB (2016) Plant-soil feedbacks: role of plant functional group and plant traits. J Ecol 104:1608-1617

Cortois R, Veen G, Duyts H, Abbas M, Strecker T, Kostenko O, Eisenhauer N, Scheu S, Gleixner G, De Deyn GB, van der Putten WH (2017) Possible mechanisms underlying abundance and diversity responses of nematode communities to plant diversity. Ecosphere 8

De Deyn GB, Raaijmakers CE, Zoomer HR, Berg MP, de Ruiter PC, Verhoef HA, Bezemer TM, van der Putten WH (2003) Soil invertebrate fauna enhances grassland succession and diversity. Nature 422:711-713

De Deyn GB, Raaijmakers CE, Van der Putten WH (2004a) Plant community development is affected by nutrients and soil biota. J Ecol 92:824-834

De Deyn GB, Raaijmakers CE, van Ruijven J, Berendse F, van der Putten WH (2004b) Plant species identity and diversity effects on different trophic levels of nematodes in the soil food web. Oikos 106:576-586

de Kroon H, Hendriks M, van Ruijven J, Ravenek J, Padilla FM, Jongejans E, Visser EJW, Mommer L (2012) Root responses to nutrients and soil biota: drivers of species coexistence and ecosystem productivity. J Ecol 100:6-15

De Long JR, Dorrepaal E, Kardol P, Nilsson MC, Teuber LM, Wardle DA (2016) Contrasting responses of soil microbial and nematode communities to warming and plant functional group removal across a post-fire boreal forest successional gradient. Ecosystems 19:339-355 
de Ruiter PC, Van Veen JA, Moore JC, Brussaard L, Hunt HW (1993) Calculation of nitrogen mineralization in soil food webs. Plant Soil 157:263-273

Ekschmitt K, Bakonyi G, Bongers M, Bongers T, Bostrom S, Dogan H, Harrison A, Nagy P, O'Donnell AG, Papatheodorou EM, Sohlenius B, Stamou GP, Wolters V (2001) Nematode community structure as indicator of soil functioning in European grassland soils. Eur J Soil Biol 37:263-268

Eskelinen A, Stark S, Mannisto M (2009) Links between plant community composition, soil organic matter quality and microbial communities in contrasting tundra habitats. Oecologia 161:113-123

Francis R, Read DJ (1994) The contributions of mycorrhizal fungi to the determination of plant community structure. Plant Soil 159:11-25

Hart MM, Reader RJ, Klironomos JN (2003) Plant coexistence mediated by arbuscular mycorrhizal fungi. Trends Ecol Evol 18:418-423

Heinen R, van der Sluijs M, Biere A, Harvey JA, Bezemer TM (2018) Plant community composition but not plant traits determine the outcome of soil legacy effects on plants and insects. J Ecol 106:1217-1229

Heinze J, Bergmann J, Rillig MC, Joshi J (2015) Negative biotic soil-effects enhance biodiversity by restricting potentially dominant plant species in grasslands. Perspect Plant Ecol 17:227-235

Hendriks M, Visser EJW, Visschers IGS, Aarts BHJ, de Caluwe H, Smit-Tiekstra AE, van der Putten WH, de Kroon H, Mommer L (2015) Root responses of grassland species to spatial heterogeneity of plant-soil feedback. Funct Ecol 29:177-186

Hodge A, Fitter AH (2013) Microbial mediation of plant competition and community structure. Funct Ecol 27:865-875

Kardol P, Bezemer TM, van der Wal A, van der Putten WH (2005) Successional trajectories of soil nematode and plant communities in a chronosequence of ex-arable lands. Biol Conserv 126:317-327

Kardol P, Cornips NJ, van Kempen MML, Bakx-Schotman JMT, van der Putten WH (2007) Microbe-mediated plant-soil feedback causes historical contingency effects in plant community assembly. Ecol Monogr 77:147-162

Klironomos JN, McCune J, Hart M, Neville J (2000) The influence of arbuscular mycorrhizae on the relationship between plant diversity and productivity. Ecol Lett 3:137-141

Kulmatiski A, Beard KH, Stevens JR, Cobbold SM (2008) Plantsoil feedbacks: a meta-analytical review. Ecol Lett 11:980992

Kulmatiski A, Anderson-Smith A, Beard KH, Doucette-Riise S, Mazzacavallo M, Nolan NE, Ramirez RA, Stevens JR (2014) Most soil trophic guilds increase plant growth: a metaanalytical review. Oikos 123:1409-1419

Laliberté E, Lambers H, Burgess TI, Wright SJ (2015) Phosphorus limitation, soil-borne pathogens and the coexistence of plant species in hyperdiverse forests and shrublands. New Phytol 206:507-521

Lawton JH (1996) The Ecotron facility at Silwood Park: the value of "big bottle" experiments. Ecology 77:665-669

Maron JL, Marler M, Klironomos JN, Cleveland CC (2011) Soil fungal pathogens and the relationship between plant diversity and productivity. Ecol Lett 14:36-41

Martinez-Garcia LB, De Deyn GB, Pugnaire FI, Kothamasi D, van der Heijden MGA (2017) Symbiotic soil fungi enhance ecosystem resilience to climate change. Glob Chang Biol 23:5228-5236

Mills KE, Bever JD (1998) Maintenance of diversity within plant communities: soil pathogens as agents of negative feedback. Ecology 79:1595-1601

Mordecai EA (2011) Pathogen impacts on plant communities: unifying theory, concepts, and empirical work. Ecol Monogr 81:429-441

Oostenbrink M (1960) Estimating nematode populations by some selected methods. In: Sasser JN, Jenkins WR (eds) Nematology. University of North Carolina Press, Chapel Hill

Peay KG (2018) Timing of mutualist arrival has a greater effect on Pinus muricata seedling growth than interspecific competition. J Ecol 106:514-523

Pellkofer S, van der Heijden MGA, Schmid B, Wagg C (2016) Soil communities promote temporal stability and species asynchrony in experimental grassland communities. PLoS One 11:e0148015

Porazinska DL, Bardgett RD, Blaauw MB, Hunt HW, Parsons AN, Seastedt TR, Wall DH (2003) Relationships at the aboveground-belowground interface: plants, soil biota, and soil processes. Ecol Monogr 73:377-395

R Development Core Team 2016. R: a language and environment for statistical computing. R Foundation for Statistical Computing, Vienna. http://www.R-project.org

Reynolds HL, Packer A, Bever JD, Clay K (2003) Grassroots ecology: plant-microbe-soil interactions as drivers of plant community structure and dynamics. Ecology 84:2281-2291

Reynolds HL, Mittelbach GG, Darcy-Hall TL, Houseman GR, Gross KL (2007) No effect of varying soil resource heterogeneity on plant species richness in a low fertility grassland. $\mathrm{J}$ Ecol 95:723-733

Scheublin TR, Van Logtestijn RSP, Van der Heijden MGA (2007) Presence and identity of arbuscular mycorrhizal fungi influence competitive interactions between plant species. J Ecol 95:631-638

Schnitzer SA, Klironomos JN, HilleRisLambers J, Kinkel LL, Reich PB, Xiao K, Rillig MC, Sikes BA, Callaway RM, Mangan SA, van Nes EH, Scheffer M (2011) Soil microbes drive the classic plant diversity-productivity pattern. Ecology 92:296-303

Smith SE, Read DJ (2008) Mycorrhizal symbiosis. Academic Press, London

Teste FP, Kardol P, Turner BL, Wardle DA, Zemunik G, Renton M, Laliberte E (2017) Plant-soil feedback and the maintenance of diversity in mediterranean-climate shrublands. Science 355:173-176

Thakur MP, Reich PB, Fisichelli NA, Stefanski A, Cesarz S, Dobies T, Rich RL, Hobbie SE, Eisenhauer N (2014) Nematode community shifts in response to experimental warming and canopy conditions are associated with plant community changes in the temperate-boreal forest ecotone. Oecologia 175:713-723

Troelstra SR, Wagenaar R, Smant W, Peters BAM (2001) Interpretation of bioassays in the study of interactions between soil organisms and plants: involvement of nutrient factors. New Phytol 150:697-706

Trudgill DL (1991) Resistance to and tolerance of plant parasitic nematodes in plants. Annu Rev Phytopathol 29:167-192 
Umbanhowar J, McCann K (2005) Simple rules for the coexistence and competitive dominance of plants mediated by mycorrhizal fungi. Ecol Lett 8:247-252

van den Brink PJ, ter Braak CJF (1999) Principal response curves: analysis of time-dependent multivariate responses of biological community to stress. Environ Toxicol Chem 18:138-148

van der Heijden MGA, Streitwolf-Engel R, Riedl R, Siegrist S, Neudecker A, Ineichen K, Boller T, Wiemken A, Sanders IR (2006) The mycorrhizal contribution to plant productivity, plant nutrition and soil structure in experimental grassland. New Phytol 172:739-752

van der Heijden MGA, Bardgett RD, van Straalen NM (2008) The unseen majority: soil microbes as drivers of plant diversity and productivity in terrestrial ecosystems. Ecol Lett 11:296-310

van der Heijden MG, de Bruin S, Luckerhoff L, van Logtestijn RS, Schlaeppi K (2016) A widespread plant-fungal-bacterial symbiosis promotes plant biodiversity, plant nutrition and seedling recruitment. Isme J 10:389-399

van der Putten WH, Peters BAM (1997) How soil-borne pathogens may affect plant competition. Ecology 78:1785-1795

van der Putten WH, Van der Stoel CD (1998) Plant parasitic nematodes and spatio-temporal variation in natural vegetation. Appl Soil Ecol 10:253-262

van der Putten WH, Vandijk C, Peters BAM (1993) Plant-specific soil-borne diseases contribute to succession in foredune vegetation. Nature 362:53-56

van der Putten WH, Bardgett RD, Bever JD, Bezemer TM, Casper BB, Fukami T, Kardol P, Klironomos JN, Kulmatiski A, Schweitzer JA, Suding KN, Van de Voorde TFJ, Wardle DA (2013) Plant-soil feedbacks: the past, the present and future challenges. J Ecol 101:265-276

van Ruijven J, De Deyn GB, Raaijmakers CE, Berendse F, van der Putten WH (2005) Interactions between spatially separated herbivores indirectly alter plant diversity. Ecol Lett 8:30-37

Verschoor BC, Pronk TE, de Goede RGM, Brussaard L (2002) Could plant-feeding nematodes affect the competition between grass species during succession in grasslands under restoration management? J Ecol 90:753-761
Viketoft M, Palmborg C, Sohlenius B, Huss-Danell K, Bengtsson J (2005) Plant species effects on soil nematode communities in experimental grasslands. Appl Soil Ecol 30:90-103

Viketoft M, Bengtsson J, Sohlenius B, Berg MP, Petchey O, Palmborg C, Huss-Danell K (2009) Long-term effects of plant diversity and composition on soil nematode communities in model grasslands. Ecology 90:90-99

Wagg C, Bender SF, Widmer F, van der Heijden MGA (2014) Soil biodiversity and soil community composition determine ecosystem multifunctionality. Proc Natl Acad Sci U S A 111: 5266-5270

Wang B, Qiu YL (2006) Phylogenetic distribution and evolution of mycorrhizas in land plants. Mycorrhiza 16:299-363

Wang M, Biere A, van der Putten WH, Bezemer TM, Brinkman EP (2017) Timing of simulated aboveground herbivory influences population dynamics of root-feeding nematodes. Plant Soil 415:215-228

Wang M, Ruan W, Kostenko O, Carvalho S, Hannula SE, Mulder PPJ, Bu F, van der Putten WH, Bezemer TM (2019) Removal of soil biota alters soil feedback effects on plant growth and defense chemistry. New Phytol 221:1478-1491

Wardle DA, Yeates GW, Williamson W, Bonner KI (2003) The response of a three trophic level soil food web to the identity and diversity of plant species and functional groups. Oikos 102:45-56

Wurst S, Allema B, Duyts H, van der Putten WH (2008) Earthworms counterbalance the negative effect of microorganisms on plant diversity and enhance the tolerance of grasses to nematodes. Oikos 117:711-718

Yeates GW, Bongers T, Degoede RGM, Freckman DW, Georgieva SS (1993) Feeding-habits in soil nematode families and genera - an outline for soil ecologists. J Nematol 25:315-331

Zak DR, Holmes WE, White DC, Peacock AD, Tilman D (2003) Plant diversity, soil microbial communities, and ecosystem function: are there any links? Ecology 84:2042-2050

Publisher's note Springer Nature remains neutral with regard to jurisdictional claims in published maps and institutional affiliations. 